\title{
ARTIFICIAL ORGANS
}

\section{Effect of Cerebral Flow Autoregulation Function on Cerebral Flow Rate under Continuous Flow Left Ventricular Assist Device Support}

\begin{tabular}{|r|l|}
\hline Journal: & Artificial Organs \\
\hline Manuscript ID & AO-00391-2017.R1 \\
\hline Manuscript Type: & Main Text \\
\hline Keywords: & $\begin{array}{l}\text { left ventricular assist device, CF-LVAD, cerebral flow, cerebral } \\
\text { autoregulatory function }\end{array}$ \\
\hline Specialty/Area of Expertise: & $\begin{array}{l}\text { LVAD, IABP < Total Artificial Heart/Cardiac \& Circulatory Assistance, } \\
\text { Biomedical Engineering, Engineering (Chem/Elec/Mech), Physics, } \\
\text { Physiology }\end{array}$ \\
\hline \multicolumn{2}{|l}{} \\
\hline
\end{tabular}




\section{Effect of Cerebral Flow Autoregulation Function on Cerebral Flow Rate under}

\section{Continuous Flow Left Ventricular Assist Device Support}

\section{Abstract}

Neurological complications in Continuous Flow Left Ventricular Assist Device (CF-LVAD) patients are the second-leading risk of death after multi-organ failure. They are associated with altered blood flow in the cardiovascular system because of CF-LVAD support. Moreover, an impaired cerebral autoregulation function may also contribute to complications such as hyperperfusion in the cerebral circulation under mechanical circulatory support. The aim of this study is to evaluate the effect of cerebral autoregulatory function on cerebral blood flow rate under CF-LVAD support. A lumped parameter model was used to simulate the cardiovascular system including the heart chambers, heart valves, systemic and pulmonary circulations and cerebral circulation which includes entire Circle of Willis. A baroreflex model was used to regulate the systemic arteriolar and cerebral vascular resistances and a model of the Micromed CFLVAD was used to simulate the pump dynamics at different operating speeds. Additionally, preserved and impaired cerebral autoregulatory functions were simulated in heart failure and under CF-LVAD support. Cerebral blood flow rate was restored under CF-LVAD support at $10500 \mathrm{rpm}$ pump operating speed which generated a similar arterial blood pressure and blood flow as in a healthy condition for the impaired cerebral autoregulatory function while the preserved cerebral autoregulatory function regulated the cerebral flow rate within a relatively low range for the applied pump operating speeds. Relatively low or high pump operating speeds may cause underpefusion or hyperperfusion for a failing cardiovascular system with impaired cerebral autoregulatory 
1 function under CF-LVAD support which will contribute to the worsening of cerebral

2 complications.

3 Keywords: left ventricular assist device, CF-LVAD, cerebral flow, cerebral

4 autoregulatory function

5 Introduction

Heart failure has a complex structure at the organ and cellular levels and it is

7 conventionally treated with inotropic support, diuretics, or moderate exercise.

8 Nevertheless, none of these treatment techniques may work and a heart transplantation

9 would be then required. However, the current state of donor organ supply means that

10 many patients are not treated, due to a lack of fitting donor organ. Continuous Flow Left

11 Ventricular Assist Devices (CF-LVADs) may be used to bridge the time between the

12 decision to transplant and the actual transplantation in these patients [1]. Although these

13 devices restore the perfusion levels in the patients' body, they alter the blood flow in the

14 cardiovascular system significantly [2,3]. Moreover, altered blood flow in the

15 cardiovascular system under CF-LVAD support may cause problems such as gastro-

16 intestinal bleeding and end-organ failure because of the reduced pulsatility, aortic valve

17 insufficiency due to altered aortic valve load or hemorrhagic stroke because of abnormal

18 cerebral flow etc., which increases the morbidity and mortality of the patients [4-8].

A possible solution for the problems occurring due to the altered blood flow in the 20 cardiovascular system may be operating the CF-LVADs at a dynamic mode instead of

21 continuous mode $[9,10]$. Some of these problems have been extensively studied and 22 dynamic CF-LVAD operating support modes have already been suggested. For instance, 
1 there have been studies proposing CF-LVAD operating speed modulation algorithms to

2 increase the arterial pulsatility in a co-pulsative pump support over a cardiac cycle [11-

3 14]. Aortic valve function and opening duration can be increased by reducing the CF-

4 LVAD operating speed to a minimum value before the onset of the systolic phase in the

5 left ventricle $[15,16]$. Myocardial recovery because of a reverse remodeling in the

6 ventricle may occur under CF-LVAD support with complete unloading of the left ventricle

7 [17]. CF-LVAD operating modes imitating Frank-Starling mechanism have also been

8 proposed to provide more physiological preloads and afterloads for the changing

9 conditions in a patient's body [18-20].

10 Neurological complications in CF-LVAD patients are the second-leading highest

11 risk after multi-organ failure [4,21]. The prevalence of cerebral micro-bleeds which are

12 positively correlated with haemorrhagic stroke is very common in CF-LVAD patients [22].

13 However, it should be noted that the causes of cerebral function problems still remains

14 unclear and may be associated with pre- and post-operative factors such as previous

15 strokes, persistent malnutrition and inflammation, severity of heart failure, and post-LVAD

16 infections, reduced pulsatility or the anatomic configuration of LVAD outflow cannula-

17 ascending aorta anastomosis [23-25].

In a healthy cardiovascular system, cerebral flow rate changes slightly within a range between $60 \mathrm{mmHg}$ and $140 \mathrm{mmHg}$ of arterial blood pressure [26]. However, in the 20 heart failure patients clinical data indicates that cerebral flow autoregulation function may 21 be impaired and there might be a mild to moderate average cerebral flow rate reduction 22 [27-29]. Moreover, cerebral flow may reduce by up to 30 percent although arterial blood 23 pressure remains within the autoregulation zone [30]. After CF-LVAD implantation, 
1 cerebral autoregulatory function reported to be preserved [31]. Nevertheless, there are

2 also studies reporting that cerebral hyper-perfusion may be observed after LVAD

3 implantation and may be associated with impaired cerebral autoregulation function

4 [32,33]. It can be concluded that the condition of cerebral flow autoregulation function

5 may be different in patients and may affect the cerebral haemodynamic signals of CF-

6 LVAD patients. Moreover, the proposed CF-LVAD operating speed regulation techniques

7 may cause more complications in a cardiovascular system with impaired cerebral flow

8 autoregulation function under heart pump support.

9 In this study, the effects of preserved and impaired cerebral autoregulation 10 functions on cerebral flow rate under CF-LVAD support have been investigated at

11 different speeds of the heart pump utilising numerical simulations. The cerebral 12 circulation model includes the entire Circle of Willis, thus enabling an accurate

13 representation of cerebral circulation. The autoregulatory mechanism regulates systemic 14 arteriolar resistance and pial circulation resistance simulating the physiological functions 15 of preserved and impaired cerebral autoregulation.

16 Materials and Methods

17 Any changes in arterial blood pressure are detected by baroreceptors in the walls

18 of the large systemic arteries and is then transmitted to the central nervous system. A 19 drop in arterial blood pressure stimulates the sympathetic nervous system. The response 20 of the cardiovascular system to a pressure drop in the large arteries is to increase the 21 systemic peripheral resistance by constricting the arterioles [34]. Therefore, the 22 autoregulation of the systemic peripheral resistance has been modelled using mean 
1 aortic pressure $\left(p_{a o, m}\right)$ in the cardiovascular system model [35]. The set point of the

2 autonomic nervous system was selected as $100 \mathrm{mmHg}$ aortic pressure and systemic

3 arteriolar resistance at this pressure was taken from [35].

$4 \quad \Delta R_{\text {ars }}=\left|S_{\text {Rars }}\left(100-p_{\text {ao,m }}\right) R_{\text {ars }, 100}\right|$

$5 \quad R_{\text {ars }}= \begin{cases}R_{\text {ars }}-\Delta R_{\text {ars }} & p_{\text {ao }, m} \geq 100 \\ R_{\text {ars }}+\Delta R_{\text {ars }} & p_{\text {ao }, m}<100\end{cases}$

6 Here, $R_{\text {ars }}, \Delta R_{\text {ars }}, R_{\text {ars }, 100}$ and $S_{\text {Rars }}$ represent systemic arteriole resistance, change

7 in the systemic arteriolar resistance, systemic arteriolar resistance at $100 \mathrm{mmHg}$ mean

8 aortic pressure and sensitivity of the systemic arteriolar resistance. In the equation above

$9 \quad 0.0175 \mathrm{mmHg}^{-1}$ and $1 \mathrm{mmHgs} / \mathrm{mL}$ were used for $S_{\text {Rars }}$ and $R_{\text {ars, }, 100}$ respectively [35].

Cerebral blood flow response is also correlated with mean systemic arterial

11 pressure [36] and the cerebral flow rate changes slightly within a range of $60 \mathrm{mmHg}$ and

$12140 \mathrm{mmHg}$ arterial pressures in healthy subjects [26]. Moreover, cerebral vessel

13 resistance changes linearly within this range in order to regulate cerebral blood flow [37].

14 However, in the heart failure patients there might be a mild to moderate average cerebral

15 flow rate reduction $[27,30]$ because of impaired cerebral autoregulation. The cerebral

16 blood flow was regulated using a varying resistance in the pial circulation as given below.

$17 \Delta R_{p c}=\left|S_{R p c}\left(100-p_{a o, m}\right) R_{p c, 100}\right|$

$18 R_{p c}= \begin{cases}R_{p c}+\Delta R_{p c} & p_{a o, m} \geq 100 \\ R_{p c}-\Delta R_{p c} & p_{a o, m}<100\end{cases}$

19 Here, $R_{p c}, \Delta R_{p c}, R_{p c, 100}$ and $S_{R p c}$ represent pial circulation resistance, change in 20 the pial circulation resistance, pial circulation resistance at $100 \mathrm{mmHg}$ mean aortic 
1 pressure and the sensitivity of the pial circulation resistance. In the equation above $S_{R p c}$

2 was $0.0120 \mathrm{mmHg}^{-1}$ for the healthy condition and preserved cerebral autoregulation for

3 heart failure. Impaired cerebral flow autoregulation was simulated by reducing $S_{R p c}$ to

$4 \quad 0.0055 \mathrm{mmHg}^{-1}$. The pial circulation resistance $\left(R_{p c, 100}\right)$ at $100 \mathrm{mmHg}$ arterial blood

5 pressure was $5 \mathrm{mmHgs} / \mathrm{mL}$. The utilised preserved and impaired cerebral flow

6 autoregulation functions together with the physiological preserved and impaired cerebral

7 flow autoregulation functions [38] have been given in Figure 1.

$8 \quad$ Numerical simulations were performed using a cardiovascular system model

9 which includes the left and right ventricles, left and right atria, heart valves, aorta, aortic 10 arch, systemic arterioles, systemic capillaries, systemic veins, pulmonary arteries,

11 pulmonary arterioles, pulmonary veins and cerebral circulation. The cerebral circulation

12 consists of pial circulation, cerebral capillaries and cerebral veins, left and right internal

13 carotid arteries, left and right vertebral arteries, basilar artery, left and right superior

14 cerebellar arteries, left and right anterior choroidal arteries, left and right ophthalmic

15 arteries, left and right middle arteries, left and right posterior cerebral arteries, left and

16 right posterior communicating arteries, left and right anterior cerebral arteries and the

17 anterior communicating artery simulating the entire Circle of Willis in the cerebral 18 circulation as well.

19 The applied ventricle models simulate the ventricular wall mechanics using 20 myocardial constitutive properties and intramyocardial pressure. Active and passive fibre 21 stresses include the myocardial constitutive laws for fibre stress and radial stress [39]. 22 The left ventricular pressure $\left(p_{/ V}\right)$, volume change $\left(d V_{V} / d t\right)$ and active fibre stress $\left(\sigma_{a}\right)$ are 23 given below. 


$$
\begin{array}{ll}
1 & p_{l v}=\left(\sigma_{f}-2 \sigma_{m, r}\right) \ln \left(1+V_{w} / V_{l}\right) / 3 \\
2 & \frac{d V_{l v}}{d t}=Q_{m v}-Q_{a v} \\
3 & \sigma_{a}=C \sigma_{a r} f\left(l_{s}\right) g(t) h\left(v_{s}\right)
\end{array}
$$

$4 \quad$ In the equations above, $\sigma_{f}$ and $\sigma_{m, r}$ represent fibre stress and radial wall stress, $V_{w}$ 5 and $V_{l v}$ are the ventricular wall volume and cavity volume respectively. $Q_{m v}$ and $Q_{a v}$ are

6 the flow rate through the heart valves. $c$ is the parameter defining the strength of the 7 ventricular contraction, $\sigma_{a r}$ is the active fibre stress and $f$, and $h$ are the functions that 8 define sarcomere length $\left(I_{s}\right)$ and sarcomere shortening velocity $\left(U_{s}\right)$ respectively. The 9 contraction of the left ventricle is activated by an activation function $\left(g_{/ v}\right)$ over a cardiac 10 cycle.

$11 g_{I v}(t)= \begin{cases}\sin ^{2}\left(\pi t / t_{\text {max }, v}\right), & t \leq t_{\text {max }, v} \\ 0, & t>t_{\text {max }, v}\end{cases}$

12 Here, $t$ and $t_{m a x, l v}$ represent the time and twitch duration in the left ventricle model

13 over a cardiac cycle. Detailed information about the full left ventricle model can be found 14 in [39]. The right ventricle was described in a similar way using different parameter 15 values.

16 The left atrium was modelled in the same way using different parameter values for 17 the wall volume, active fibre stress, and activation function. The contraction of the left 18 atrium is driven by an activation function $\left(g_{l a}\right)$ as given below.

$19 g_{l a}(t)= \begin{cases}0, & t \leq t_{l a} \\ \sin ^{2}\left(\pi t / t_{\text {max }, a}\right), & t>t_{l a}\end{cases}$ 
1 In the equation above, $t_{l a}$ and $t_{\max , l a}$ are the time that left atrial contraction onsets and left

2 atrial twitch duration over a cardiac cycle.

3 The circulatory system was described using a lumped parameter model including

4 electrical analogues for resistance $(R)$, compliance $(C)$ and inertia $(L)$. The heart valves

5 were modelled as ideal diodes allowing one-way blood flow. In this system, the change of

6 pressure $\left(d p_{a d} d t\right)$ and the change of flow rate $\left(d Q_{a d} d t\right)$ in the aorta has been given

7 below.

$8 \quad \frac{d p_{a o}}{d t}=\frac{Q_{a o}-Q_{a v}}{C_{a o}}$

$9 \quad \frac{d Q_{a o}}{d t}=\frac{p_{a o}-p_{a a}-R_{a o} Q_{a o}}{L_{a o}}$

10 In the equations above, $Q_{a v}$ is the flow rate through the aortic valve, and $p_{a o}$ is the

11 pressure in the aorta. $C_{a o}, R_{a o}$ and $L_{a o}$ represent the aortic compliance, resistance and

12 inertance respectively. The change of the pressures and flow rates in the other

13 compartments were modelled in the same way using different parameter values.

The circle of Willis is a ring of interconnecting arteries located at the base of the

15 brain and is composed of anterior cerebral arteries, anterior communicating artery,

16 internal carotid arteries, posterior cerebral arteries and posterior communicating arteries.

17 These blood vessels are supplied with blood by the vertebral and basilar arteries and

18 distribute the blood to the superior cerebellar arteries, middle cerebral arteries, anterior

19 choroidal arteries and ophthalmic arteries [40]. In the cerebral circulation model, the

20 internal carotid and vertebral arteries were modelled using resistance and inertance

21 properties, and the rest of the cerebral circulation includes resistance, and compliance 
1 properties (Fig. 2) using a similar relationship as described in Eq. 6 and Eq. 7. Generally,

2 blood flow is distributed uniformly and does not vary considerably in each section on the

3 left and right sides unless there are significant anatomical variations or anomalies in the

4 structure of the cerebral arteries [41,42]. Therefore, in this study all of the blood vessels

5 on the left and right sections are assumed to be identical. Resistances $(R)$ were

6 estimated using the Poiseuille equation for each compartment in the Circle of Willis and

7 for cerebral circulation as given below.

$8 R=\frac{8 \mu}{\pi r^{4}} I$

$9 \quad$ Here, $\mu, r$ and $I$ are the blood viscosity, inner radius and length of the blood

10 vessels. The base values for blood vessel inner radiuses and lengths are taken from [38]

11 to estimate the resistances for the cerebral circulation. It should be noted that resistance

12 of the blood vessels in Circle of Willis and cerebral circulation varies within a large range

13 and significantly different values have been reported [41,43-48]. Such large variations in

14 the blood vessel lengths and inner radiuses cause a large variation in resistances.

15 Therefore, the resistance of the blood vessels in the cerebral circulation were adjusted

16 manually around the base values taken from [38] to obtain the physiological flow rates in

17 the cerebral circulation and Circle of Willis flow rates.

A dilated cardiomyopathy (DCM) condition was simulated as the pathological case

19 in this study. Dilated cardiomyopathy is a condition in which the heart's ability to pump

20 blood is decreased because the left ventricle is enlarged and weakened. It is

21 characterised with reduced contractility, increased left ventricular volume and elevated

22 left ventricular filling pressures [1]. To simulate dilated cardiomyopathy, the contractility of 
1 the left ventricle $(c)$ was reduced from 1 to 0.60 . The left ventricular wall volume was

2 increased from $200 \mathrm{~mL}$ to $225 \mathrm{~mL}$, zero pressure left-ventricular volume, increased from

$30.3 V_{l v}$ to $0.4 V_{l V}$ as defined in [39]. All of the parameter values used in the systemic,

4 pulmonary and cerebral circulations, left and right ventricles and left and right atria have

5 been given in the Appendix section.

6 To simulate CF-LVAD support, a model which estimates the pressure difference

7 across the Micromed heart pump considering the operating speed of the pump, flow rate

8 and change of the flow rate through the pump [49] was integrated into the cardiovascular

9 system model:

$10 \Delta p_{C F-L V A D}=K \omega_{C F-L V A D}^{2}-R_{C F-L V A D} Q_{C F-L V A D}-L_{C F-L V A D} \frac{d Q_{C F-L V A D}}{d t}$

$11 R_{C F-L V A D}=k_{1} Q_{C F-L V A D}+k_{2}$

12 In the equations above, $\Delta p_{C F-L V A D}$ and $Q_{C F-L V A D}$ denote the pressure difference

13 across the pump and flow rate through the pump. $L_{C F-L V A D}(2 \mathrm{e}-2 \mathrm{mmHg} \mathrm{s} / \mathrm{mL})$ and $R_{C F-}$

$14 L V A D$ are the inertance and resistance effects in the pump. $K\left(8.56 \mathrm{e}-05 \mathrm{mmHg} \mathrm{s}{ }^{2} / \mathrm{rad}^{2}\right), k_{1}$

$15 \quad\left(9.17 \mathrm{e}-04 \mathrm{mmHg} \mathrm{s}{ }^{2} / \mathrm{mL}^{2}\right)$ and $k_{2}(203 \mathrm{e}-3 \mathrm{mmHg} \mathrm{s} / \mathrm{mL})$ are the estimated parameters [49]

16 and $\omega_{C F-L V A D}$ denotes the operating speed of the pump. The electric analogue of

17 cardiovascular system, CF-LVAD and cerebral circulation models together with a

18 schematic of circle of Willis have been given Figure 2. The abbreviations used in Figure 2

19 have been listed in the Appendix section.

20 The simulations were performed using Matlab Simulink R2017a. The set of 21 equations was solved using the ode15s solver. The maximum step size was 1e-3 s, 22 relative tolerance was set to $1 \mathrm{e}-3$. The CF-LVAD was operated between $7500 \mathrm{rpm}$ and 
$112500 \mathrm{rpm}$ rotation speeds with $1000 \mathrm{rpm}$ intervals. The heart rate was kept at $75 \mathrm{bpm}$

2 for all of the conditions in the numerical simulations.

\section{Results}

First, the simulations were performed for the healthy cardiovascular system model

5 and DCM cardiovascular system models with preserved and impaired cerebral

6 autoregulatory functions. The left ventricular and atrial pressures, aortic pressure and left

7 ventricular and atrial volumes for the healthy condition and DCM conditions with

8 preserved and impaired cerebral flow autoregulation functions have been given in Figure 93.

The healthy cardiovascular system model simulates the pressure and volume

11 signals within the normal physiological range. Peak left ventricular pressure is around

$12125 \mathrm{mmHg}$ for the healthy cardiovascular system model. Reduced contraction in the left

13 ventricle decreases the peak left ventricular and aortic pressures while increasing the 14 diastolic left ventricular and atrial pressures in both DCM models with preserved and 15 impaired cerebral flow autoregulation functions. Left ventricular volume changes between $1650 \mathrm{~mL}$ and $116 \mathrm{~mL}$ in the healthy model. Left ventricular volume increased significantly in 17 both DCM models with preserved and impaired cerebral flow autoregulation functions 18 while left atrial volume increased slightly. The mean aortic pressure, cardiac output and 19 mean pump output under CF-LVAD support for the healthy cardiovascular system model, 20 DCM cardiovascular system models with preserved and impaired cerebral flow 21 autoregulation functions with and without CF-LVAD support have been given in Table 1. 
The mean aortic pressure and cardiac output decreases in the DCM models with

2 respect to the healthy model. CF-LVAD support generates similar mean arterial

3 pressures and blood flow rates as in the healthy cardiovascular system model for the

4 DCM models with preserved and impaired cerebral autoregulation functions at 10500

5 rpm pump operating speed. The mean aortic pressures, cardiac outputs and mean pump

6 outputs were similar for the simulated physiological conditions at different CF-LVAD

7 operating speeds. Flow rate signals in the internal carotid arteries, vertebral arteries,

8 basilar artery, posterior cerebral arteries, anterior cerebral arteries and middle cerebral

9 arteries are given for the healthy cardiovascular system model and DCM cardiovascular

10 system models with preserved and impaired cerebral flow autoregulation functions in

11 Figure 4. The presented results for the blood flow rate in the cerebral circulation shows

12 only one side since the same parameter values were used and the same results have

13 been obtained for the blood vessels in left and right compartments of the cerebral 14 circulation. $475 \mathrm{~mL} / \mathrm{min}$ while the vertebral arterial blood flow rate variation is between $46 \mathrm{~mL} / \mathrm{min}$

17 and $146 \mathrm{~mL} / \mathrm{min}$ over a cardiac cycle in the healthy cardiovascular system. Changes in

18 the basilar arterial flow rate over a cardiac cycle were between $94 \mathrm{~mL} / \mathrm{min}$ and 290

$19 \mathrm{~mL} / \mathrm{min}$, posterior and anterior arterial blood flow rates change between $30 \mathrm{~mL} / \mathrm{min}$ and

$2090 \mathrm{ml} / \mathrm{min}$ and $50 \mathrm{ml} / \mathrm{min}$ and $157 \mathrm{~mL} / \mathrm{min}$ and middle arterial blood flow rate changes

21 between $77 \mathrm{ml} / \mathrm{min}$ and $245 \mathrm{ml} / \mathrm{min}$ in the healthy cardiovascular system. Blood flow

22 rates in the internal carotid arteries, vertebral arteries, basilar artery, posterior cerebral

23 arteries, anterior cerebral arteries and middle cerebral arteries reduced in the DCM 
1 cardiovascular system models. Amplitudes of the flow rate signals in these

2 compartments decreased for the DCM cardiovascular system models as well. Mean flow

3 rates in the internal carotid arteries, vertebral arteries, basilar artery, posterior cerebral

4 arteries, anterior cerebral arteries and middle cerebral arteries for the healthy

5 cardiovascular system model, DCM cardiovascular system models with preserved and

6 impaired cerebral flow autoregulation functions with and without CF-LVAD support have

7 been given in Figure 5.

The mean flow rate in the in the internal carotid arteries, vertebral arteries and

9 basilar artery were $274 \mathrm{~mL} / \mathrm{min}, 82 \mathrm{~mL} / \mathrm{min}$ and $162 \mathrm{~mL} / \mathrm{min}$ respectively in the healthy

10 cardiovascular system. The mean flow rate in the posterior cerebral arteries, anterior

11 cerebral arteries and middle cerebral arteries were $51 \mathrm{~mL} / \mathrm{min}, 87 \mathrm{~mL} / \mathrm{min}$ and 136

$12 \mathrm{~mL} / \mathrm{min}$ respectively in the healthy cardiovascular system. Blood flow rates in each

13 compartment of cerebral circulation decreased for the DCM cardiovascular system

14 models due to a reduced contractility and arterial pressure. The decrease in the blood

15 flow rates for the DCM cardiovascular system models with impaired cerebral flow

16 autoregulation function is significantly higher with respect to the DCM cardiovascular

17 system model with preserved cerebral flow autoregulation function. CF-LVAD support

18 increases the blood flow rate the cerebral circulation slightly until the pump operating

19 speed becomes $9500 \mathrm{rpm}$ in the DCM cardiovascular system model with preserved

20 cerebral flow autoregulation function. Blood flow rates in the each compartment of the

21 cerebral circulation reduced after $10500 \mathrm{rpm}$ pump speed except in the internal carotid

22 arteries. Increasing the pump operating speed reduces the blood flow rate slightly in this

23 compartment as well for the DCM cardiovascular system model with preserved cerebral 
1 flow autoregulation function. Blood flow rates increased in the compartments of the

2 cerebral circulation for the DCM cardiovascular system models with impaired cerebral

3 flow autoregulation function with the increasing CF-LVAD operating speeds. At 10500

4 rpm pump operating speed blood flow rates in the compartments of the cerebral

5 circulation are almost the same to the healthy cardiovascular system model. The total

6 mean blood flow rate in the cerebral circulation for both DCM cardiovascular system

7 models with preserved and impaired cerebral flow autoregulation functions with and

8 without CF-LVAD support have been given in Figure 6.

9 Total mean blood flow rate was around $710 \mathrm{~mL} / \mathrm{min}$ for the healthy cardiovascular 10 system model. It decreased to $680 \mathrm{~mL} / \mathrm{min}$ in the DCM cardiovascular system model with

11 preserved cerebral flow autoregulation function. The blood flow rate increased with the

12 increasing pump operating speed until the pump operating speed becomes $10500 \mathrm{rpm}$

13 and started to decrease at the higher CF-LVAD operating speeds. The total mean flow

14 rate was around $601 \mathrm{~mL} / \mathrm{min}$ for the $\mathrm{DCM}$ cardiovascular system model with impaired 15 cerebral flow autoregulation function and it increased with the increasing pump operating

16 speed. At 10500 rpm CF-LVAD operating speed, the total mean cerebral blood flow rate 17 was around $710 \mathrm{~mL} / \mathrm{min}$ and $715 \mathrm{~mL} / \mathrm{min}$ for the $\mathrm{DCM}$ cardiovascular system models 18 with preserved and impaired cerebral autoregulation functions respectively. The flow rate 19 signal amplitudes in the internal carotid arteries, vertebral arteries, basilar artery, 20 posterior cerebral arteries, anterior cerebral arteries and middle cerebral arteries for the 21 healthy cardiovascular system model, DCM cardiovascular system models with 22 preserved and impaired cerebral flow autoregulation functions with and without CF-LVAD 23 support have been given in Figure 7. 
Flow rate signal amplitudes in each compartment shown in Figure 7 reduced in

2 the DCM cardiovascular system models with respect to the healthy cardiovascular

3 system model. CF-LVAD support decreased the flow rate signal amplitudes further.

4 However, the flow rate signal amplitudes are similar for both DCM models under CF-

5 LVAD support. Vascular resistances in the pial circulation and systemic peripheral

6 circulation for the healthy cardiovascular system model, DCM cardiovascular system

7 models with preserved and impaired cerebral flow autoregulation functions with and

8 without CF-LVAD support have been given in Figure 8.

The resistance of the pial and systemic peripheral circulations are $5 \mathrm{mmHgs} / \mathrm{mL}$

10 and $1 \mathrm{mmHgs} / \mathrm{mL}$ as the set points of autoregulation function in the healthy

11 cardiovascular system. The resistance of pial circulation decreased in the DCM

12 cardiovascular system models. The preserved cerebral flow autoregulation function

13 reduced the pial circulation resistance more with respect to the impaired cerebral flow

14 autoregulation function in the DCM cardiovascular system models. CF-LVAD support

15 increased the resistance of the pial circulation in both DCM cardiovascular system

16 models. The resistance of pial circulation is more sensitive to the CF-LVAD operating

17 speed changes for the preserved cerebral flow autoregulation function with respect to the

18 impaired cerebral flow autoregulation function. Again, at $10500 \mathrm{rpm}$ pump operating

19 speed, the pial circulation resistance in the DCM cardiovascular system models with

20 preserved and impaired autoregulation functions was similar to the resistance in the

21 healthy cardiovascular system model. The systemic peripheral resistance in DCM

22 cardiovascular system models increased with respect to the healthy cardiovascular

23 system model. CF-LVAD support reduced the systemic peripheral resistance similarly 
1 for the both DCM cardiovascular system models with preserved and impaired

2 autoregulatory functions.

3 Discussion

$4 \quad$ In this study, the effect of cerebral autoregulatory function on the cerebral

5 haemodynamic signals under CF-LVAD support was assessed using a numerical model,

6 which described the heart, systemic and pulmonary circulations and cerebral circulation

7 and a heart pump. The cerebral circulation model included the entire Circle of Willis

8 enabling for an accurate representation of cerebral circulation. Additionally, the flow rate

9 in the systemic arteriolar and cerebral circulations were regulated using a baroreflex

10 model for the resistances in these sections. For a healthy condition average flow rate

11 through internal carotid arteries and vertebral arteries are around $730 \mathrm{~mL} / \mathrm{min}$, however,

12 this value changes within a large variation range $[42,50]$. The blood flow rate through the

13 internal carotid arteries and vertebral arteries was $710 \mathrm{~mL} / \mathrm{min}$ being within the

14 physiological range for the healthy cardiovascular system. The flow rate in the internal

15 carotid arteries changed between $165 \mathrm{~mL} / \mathrm{min}$ and $475 \mathrm{~mL} / \mathrm{min}$ over a cardiac cycle.

16 Additionally, the flow rate in the vertebral arteries changed between $46 \mathrm{~mL} / \mathrm{min}$ and 146

$17 \mathrm{~mL} / \mathrm{min}$ over a cardiac cycle. As mentioned before, the variation range of the flow rate in

18 the internal carotid arteries and vertebral arteries is quite high. The average of flow rate

19 signals obtained from the clinical data [50] shows a similar variation range to the flow rate

20 signals simulated in the healthy cardiovascular system over a cardiac cycle. Mean blood

21 flow rates over a cardiac cycle for other compartments of cerebral circulation that have

22 been presented in this paper (Fig. 5) correspond to clinical data $[42,51,52]$ as well

23 validating the accuracy of the healthy cardiovascular system model. The utilised 
1 baroreflex model used for regulating the vascular resistances simulated the preserved

2 and impaired physiological cerebral autoregulation functions accurately for the operating

3 range of the CF-LVAD (Fig. 1).

$4 \quad$ Middle cerebral arterial blood flow velocity or blood flow rate is used an index of 5 perfusion for the cerebral circulation. Increasing CF-LVAD operating speed may reduce

6 the cerebral blood flow velocity for a resting condition [53]. CF-LVAD support reduced the

7 blood flow rate for the pump operating speeds higher than $10500 \mathrm{rpm}$ operating speed

8 though the middle cerebral arteries and the rest of the cerebral circulation slightly in DCM

9 cardiovascular system model with preserved autoregulatory function as reported in the 10 literature [53]. The mean cerebral flow rate increased for increasing CF-LVAD operating

11 speed in the DCM cardiovascular system model with impaired cerebral autoregulatory

12 function. Moreover, the change in the mean cerebral flow rate was much higher in this

13 numerical model when the pump was operating at different rotation speeds. The mean

14 flow rates for the presented compartments of the cerebral circulation and for the entire 15 cerebral circulation were similar for both DCM cardiovascular system models at 10500

16 rpm pump operating speed under CF-LVAD support. Moreover, the mean flow rates in

17 the cerebral circulation at 10500 rpm pump operating speed were similar to the healthy

18 cardiovascular system model as well. The Micromed heart pump nominally operates at

$1910500 \mathrm{rpm}$ in the patients generating sufficient blood flow rate and pressure levels. The

20 simulation results also show that at $10500 \mathrm{rpm}$ pump operating speed, the mean aortic

21 blood pressures and mean pump outputs for both DCM models are similar to the healthy

22 cardiovascular system model. This result suggests that cerebral flow rate is restored

23 under CF-LVAD support at a pump speed generating similar flow rate pressure levels to 
1 a healthy cardiovascular system although the cerebral autoregulatory function may

2 remain impaired. However, the suggested pump operating speed regulation techniques

3 to avoid the harmful effects of CF-LVAD support in the literature may generate different

4 flow rate and arterial pressure levels with respect to the healthy cardiovascular system.

5 Moreover, as reported in the literature, pulsatile LVAD support may cause hyperperfusion

6 in the cerebral circulation for an impaired cerebral auroregulatory function [33]. This may

7 also occur in the heart failure patients with impaired cerebral autoregulatory function if

8 the CF-LVAD operating speed is regulated under varying speed heart pump support.

9 Amplitudes of flow rate signals were similar for both DCM cardiovascular system models

10 with preserved and impaired autoregulatory functions under CF-LVAD support at

11 different pump operating speeds. However, the mean flow rates in the cerebral

12 circulation were different for both DCM cardiovascular system models under CF-LVAD

13 support except when operating at $10500 \mathrm{rpm}$. The ratio between the flow rate signal

14 amplitude and mean flow rate over a cardiac cycle is used as an index of pulsatility [54].

15 Therefore, the index of pulsatility is different for the DCM cardiovascular system models

16 with preserved and impaired autoregulatory functions under CF-LVAD support except at

17 the $10500 \mathrm{rpm}$ operating speed. So, the condition of the patients' cerebral autoregulatory

18 function may also play a role on the cerebral circulation problems associated with

19 pulsatility under varying speed CF-LVAD support.

In this study, performance of the left ventricle was kept the same for the DCM and

21 CF-LVAD supported cardiovascular system models. Therefore, the aortic valve remains

22 closed over a cardiac cycle for the pump operating speeds higher than $8500 \mathrm{rpm}$.

23 Nevertheless, such a result simulates the short term response of a left ventricle to the 
1 CF-LVAD implantation accurately [55]. The performance of the left ventricle might

2 improve and pulse recovery may occur in some patients over time [55,56]. In this case,

3 the aortic valve opens at the nominal Micromed Pump operating speeds in the patient

4 body and the CF-LVAD provides a partial support. However, the exact mechanism of this

5 pulse recovery is not clear, therefore, it was not included in the cardiovascular system

6 model. In any case, the baroreflex model utilised in this study uses the mean aortic

7 pressure to regulate the cerebral flow rate. Therefore, the flow rate in the cerebral

8 circulation will be regulated regardless of a partial or full CF-LVAD support in the 9 numerical model.

10 In this study, Micromed pump model was used to simulate the mechanical

11 circulatory support. Different CF-LVADs such as HeartMate II or HeartWare are widely

12 used in the clinics. Again, it should be noted that the baroreflex model utilised in this

13 study uses the mean aortic pressure to regulate the cerebral flow rate and the flow rate in

14 the cerebral circulation will be regulated regardless of the implanted CF-LVAD type.

15 However, the CF-LVAD flow rate-pressure characteristics will have an effect on the mean

16 aortic pressure along with the left ventricular contractility.

17 Conclusions

Cerebral blood flow rate is restored under CF-LVAD support at a pump operating

19 speed generating similar arterial blood pressure and blood flow rate levels as in a healthy

20 condition for an impaired cerebral autoregulatory function while a preserved cerebral

21 autoregulatory function regulated the cerebral flow rate within a relatively low range for

22 the applied pump operating speeds. Relatively low or high pump operating speeds may 
cause underpefusion or hyperperfusion in the cerebral circulation for a failing cardiovascular system with impaired cerebral autoregulatory function under CF-LVAD support. Although, an altered blood flow under CF-LVAD support is associated with cerebral circulatory complications, any failure in the cerebral autoregulatory function may worse the problems when the pump speed is regulated.

Disclosure

The authors declare no conflict of interest.

\section{References}

[1] P. Libby, R.O. Bonow, D. Mann, D.P. Zipes, Braunwald's Heart Disease: A Textbook of Cardiovascular Medicine, Single Volume, 8e, 8 edition, Saunders, Philadelphia, 2007.

[2] A. Sen, J.S. Larson, K.B. Kashani, S.L. Libricz, B.M. Patel, P.K. Guru, C.M. Alwardt, O. Pajaro, J.C. Farmer, Mechanical circulatory assist devices: a primer for critical care and emergency physicians, Crit. Care. 20 (2016). doi:10.1186/s13054-016-1328-z.

[3] Q. Zhang, B. Gao, Y. Chang, The study on hemodynamic effect of series type LVAD on aortic blood flow pattern: a primary numerical study, Biomed. Eng. OnLine. 15 (2016). doi:10.1186/s12938-016-0252-4.

[4] A. Bhimaraj, C. Uribe, E.E. Suarez, Physiological Impact of Continuous Flow on End-Organ Function: Clinical Implications in the Current ERA of Left Ventricular Assist Devices, Methodist DeBakey Cardiovasc. J. 11 (2015) 12-17. doi:10.14797/mdcj-11-1-12.

[5] E.M. Schumer, M.C. Black, G. Monreal, M.S. Slaughter, Left ventricular assist devices: current controversies and future directions, Eur. Heart J. 37 (2016) 3434-3439. doi:10.1093/eurheartj/ehv590.

[6] A. Tsiouris, G. Paone, H.W. Nemeh, J. Borgi, C.T. Williams, D.E. Lanfear, J.A. Morgan, Short and long term outcomes of 200 patients supported by continuous-flow left ventricular assist devices, World J. Cardiol. 7 (2015) 792-800. doi:10.4330/wjc.v7.i11.792.

[7] A. Tsiouris, G. Paone, H.W. Nemeh, R.J. Brewer, J. Borgi, A. Hodari, J.A. Morgan, Lessons learned from 150 continuous-flow left ventricular assist devices: a single institutional 7 year experience, ASAIO J. Am. Soc. Artif. Intern. Organs 1992. 61 (2015) 266-273. doi:10.1097/MAT.0000000000000191.

[8] S.J. Park, C.A. Milano, A.J. Tatooles, J.G. Rogers, R.M. Adamson, D.E. Steidley, G.A. Ewald, K.S. Sundareswaran, D.J. Farrar, M.S. Slaughter, HeartMate II Clinical Investigators, Outcomes in advanced heart failure patients with left ventricular assist devices for destination therapy, Circ. Heart Fail. 5 (2012) 241-248. doi:10.1161/CIRCHEARTFAILURE.111.963991.

[9] S. Bozkurt, Physiologic outcome of varying speed rotary blood pump support algorithms: a review study, Australas. Phys. Eng. Sci. Med. 39 (2016) 13-28. doi:10.1007/s13246-0150405-y. 
[10] D.S. Petukhov, D.V. Telyshev, Control Algorithms for Rotary Blood Pumps Used in Assisted Circulation, Biomed. Eng. 50 (2016) 157-160. doi:10.1007/s10527-016-9609-z.

[11] M. Ando, T. Nishimura, Y. Takewa, K. Yamazaki, S. Kyo, M. Ono, T. Tsukiya, T. Mizuno, Y. Taenaka, E. Tatsumi, Electrocardiogram-synchronized rotational speed change mode in rotary pumps could improve pulsatility, Artif. Organs. 35 (2011) 941-947. doi:10.1111/j.1525-1594.2011.01205.x.

[12] F. Huang, X. Ruan, X. Fu, Pulse-pressure-enhancing controller for better physiologic perfusion of rotary blood pumps based on speed modulation, ASAIO J. Am. Soc. Artif. Intern. Organs 1992. 60 (2014) 269-279. doi:10.1097/MAT.0000000000000059.

[13] S. Bozkurt, F.N. van de Vosse, M.C.M. Rutten, Enhancement of Arterial Pressure Pulsatility by Controlling Continuous-Flow Left Ventricular Assist Device Flow Rate in Mock Circulatory System, J. Med. Biol. Eng. 36 (2016) 308-315. doi:10.1007/s40846-016-0140-1.

[14] S. Bozkurt, S. van Tuijl, F.N. van de Vosse, M.C.M. Rutten, Arterial pulsatility under phasic left ventricular assist device support, Biomed. Mater. Eng. 27 (2016) 451-460. doi:10.3233/BME-161599.

[15] E. Tuzun, I.D. Gregoric, J.L. Conger, K. Golden, R. Jarvik, O.H. Frazier, K.A. Kadipasaoglu, The effect of intermittent low speed mode upon aortic valve opening in calves supported with a Jarvik 2000 axial flow device, ASAIO J. Am. Soc. Artif. Intern. Organs 1992. 51 (2005) 139-143.

[16] Y. Kishimoto, Y. Takewa, M. Arakawa, A. Umeki, M. Ando, T. Nishimura, Y. Fujii, T. Mizuno, M. Nishimura, E. Tatsumi, Development of a novel drive mode to prevent aortic insufficiency during continuous-flow LVAD support by synchronizing rotational speed with heartbeat, J. Artif. Organs Off. J. Jpn. Soc. Artif. Organs. 16 (2013) 129-137. doi:10.1007/s10047-0120685-x.

[17] F. Moscato, M. Arabia, F.M. Colacino, P. Naiyanetr, G.A. Danieli, H. Schima, Left ventricle afterload impedance control by an axial flow ventricular assist device: a potential tool for ventricular recovery, Artif. Organs. 34 (2010) 736-744. doi:10.1111/j.15251594.2010.01066.x.

[18] N.R. Gaddum, M. Stevens, E. Lim, J. Fraser, N. Lovell, D. Mason, D. Timms, R. Salamonsen, Starling-Like Flow Control of a Left Ventricular Assist Device: In Vitro Validation, Artif. Organs. 38 (2014) E46-E56. doi:10.1111/aor.12221.

[19] M.A. Bakouri, R.F. Salamonsen, A.V. Savkin, A.-H.H. AlOmari, E. Lim, N.H. Lovell, A Sliding Mode-Based Starling-Like Controller for Implantable Rotary Blood Pumps, Artif. Organs. 38 (2014) 587-593. doi:10.1111/aor.12223.

[20] R.F. Salamonsen, V. Pellegrino, J.F. Fraser, K. Hayes, D. Timms, N.H. Lovell, C. Hayward, Exercise studies in patients with rotary blood pumps: cause, effects, and implications for starling-like control of changes in pump flow, Artif. Organs. 37 (2013) 695-703. doi:10.1111/aor.12070.

[21] J.K. Kirklin, D.C. Naftel, F.D. Pagani, R.L. Kormos, L.W. Stevenson, E.D. Blume, M.A. Miller, J.T. Baldwin, J. Timothy Baldwin, J.B. Young, Sixth INTERMACS annual report: a 10,000-patient database, J. Heart Lung Transplant. Off. Publ. Int. Soc. Heart Transplant. 33 (2014) 555-564. doi:10.1016/j.healun.2014.04.010.

[22] D. Yoshioka, S. Okazaki, K. Toda, S. Murase, S. Saito, K. Domae, S. Miyagawa, Y. Yoshikawa, T. Daimon, M. Sakaguchi, Y. Sawa, Prevalence of Cerebral Microbleeds in Patients With Continuous-Flow Left Ventricular Assist Devices, J. Am. Heart Assoc. 6 (2017) e005955. doi:10.1161/JAHA.117.005955.

[23] T.S. Kato, P.C. Schulze, J. Yang, E. Chan, K. Shahzad, H. Takayama, N. Uriel, U. Jorde, M. Farr, Y. Naka, D. Mancini, Pre-operative and post-operative risk factors associated with neurologic complications in patients with advanced heart failure supported by a left ventricular assist device, J. Heart Lung Transplant. Off. Publ. Int. Soc. Heart Transplant. 31 (2012) 1-8. doi:10.1016/j.healun.2011.08.014. 
[24] N. Moazami, W.P. Dembitsky, R. Adamson, R.J. Steffen, E.G. Soltesz, R.C. Starling, K. Fukamachi, Does pulsatility matter in the era of continuous-flow blood pumps?, J. Heart Lung Transplant. Off. Publ. Int. Soc. Heart Transplant. 34 (2015) 999-1004. doi:10.1016/j.healun.2014.09.012.

[25] T.S. Kato, T. Ota, P.C. Schulze, M. Farr, U. Jorde, H. Takayama, Y. Naka, T. Yamashita, D.M. Mancini, Asymmetric pattern of cerebrovascular lesions in patients after left ventricular $\begin{array}{lllll}\text { assist device } \quad \text { implantation, } & \text { Stroke. } & 43 & \text { (2012) }\end{array}$ doi:10.1161/STROKEAHA.111.639682.

[26] J.E. Hall, Guyton and Hall Textbook of Medical Physiology, 13e, 13 edition, Saunders, Philadelphia, PA, 2015.

[27] G. Loncar, B. Bozic, T. Lepic, S. Dimkovic, N. Prodanovic, Z. Radojicic, V. Cvorovic, N. Markovic, M. Brajovic, N. Despotovic, B. Putnikovic, V. Popovic-Brkic, Relationship of reduced cerebral blood flow and heart failure severity in elderly males, Aging Male Off. J. Int. Soc. Study Aging Male. 14 (2011) 59-65. doi:10.3109/13685538.2010.511326.

[28] T. Lepic, G. Loncar, B. Bozic, D. Veljancic, B. Labovic, Z. Krsmanovic, M. Lepic, R. Raicevic, Cerebral blood flow in the chronic heart failure patients, Perspect. Med. 1 (2012) 304-308. doi:10.1016/j.permed.2012.02.057.

[29] J.R. Caldas, R.B. Panerai, V.J. Haunton, J.P. Almeida, G.S.R. Ferreira, L. Camara, R.C. Nogueira, E. Bor-Seng-Shu, M.L. Oliveira, R.R.V. Groehs, L. Ferreira-Santos, M.J. Teixeira, F.R.B.G. Galas, T.G. Robinson, F.B. Jatene, L.A. Hajjar, Cerebral blood flow autoregulation in ischemic heart failure, Am. J. Physiol. Regul. Integr. Comp. Physiol. 312 (2017) R108R113. doi:10.1152/ajpregu.00361.2016.

[30] N. Gruhn, F.S. Larsen, S. Boesgaard, G.M. Knudsen, S.A. Mortensen, G. Thomsen, J. Aldershvile, Cerebral blood flow in patients with chronic heart failure before and after heart transplantation, Stroke. 32 (2001) 2530-2533.

[31] W.K. Cornwell, T. Tarumi, V.L. Aengevaeren, C. Ayers, P. Divanji, Q. Fu, D. Palmer, M.H. Drazner, D.M. Meyer, B.T. Bethea, J.L. Hastings, N. Fujimoto, S. Shibata, R. Zhang, D.W. Markham, B.D. Levine, Effect of pulsatile and nonpulsatile flow on cerebral perfusion in patients with left ventricular assist devices, J. Heart Lung Transplant. Off. Publ. Int. Soc. Heart Transplant. 33 (2014) 1295-1303. doi:10.1016/j.healun.2014.08.013.

[32] K. Lietz, K. Brown, S.S. Ali, M. Colvin-Adams, A.J. Boyle, D. Anderson, A.D. Weinberg, L.W. Miller, S. Park, R. John, R.M. Lazar, The role of cerebral hyperperfusion in postoperative neurologic dysfunction after left ventricular assist device implantation for endstage heart failure, J. Thorac. Cardiovasc. Surg. 137 (2009) 1012-1019. doi:10.1016/j.jtcvs.2008.11.034.

[33] J. Bellapart, G.S. Chan, Y.-C. Tzeng, P. Ainslie, A.G. Barnett, K.R. Dunster, R. Boots, J.F. Fraser, The effect of Ventricular Assist Devices on cerebral autoregulation: A preliminary study, BMC Anesthesiol. 11 (2011) 4. doi:10.1186/1471-2253-11-4.

[34] R.E. Klabunde, Cardiovascular Physiology Concepts, 2nd Revised edition edition, Lippincott Williams \& Wilkins, Philadelphia, PA, 2011.

[35] B.W. Smith, S. Andreassen, G.M. Shaw, P.L. Jensen, S.E. Rees, J.G. Chase, Simulation of cardiovascular system diseases by including the autonomic nervous system into a minimal model, Comput. Methods Programs Biomed. 86 (2007) 153-160. doi:10.1016/j.cmpb.2007.02.001.

[36] C.K. Willie, Y.-C. Tzeng, J.A. Fisher, P.N. Ainslie, Integrative regulation of human brain blood flow, J. Physiol. 592 (2014) 841-859. doi:10.1113/jphysiol.2013.268953.

[37] M.A. Rezaienia, G. Paul, E. Avital, A. Rahideh, M.T. Rothman, T. Korakianitis, In-vitro investigation of cerebral-perfusion effects of a rotary blood pump installed in the descending aorta, J. Biomech. 49 (2016) 1865-1872. doi:10.1016/j.jbiomech.2016.04.027. 
[38] M. Ursino, M. Giannessi, A model of cerebrovascular reactivity including the circle of willis and cortical anastomoses, Ann. Biomed. Eng. 38 (2010) 955-974. doi:10.1007/s10439-0109923-7.

[39] L.G.E. Cox, S. Loerakker, M.C.M. Rutten, B.A.J.M. De Mol, F.N. Van De Vosse, A Mathematical Model to Evaluate Control Strategies for Mechanical Circulatory Support, Artif. Organs. 33 (2009) 593-603. doi:10.1111/j.1525-1594.2009.00755.x.

[40] Z. Vrselja, H. Brkic, S. Mrdenovic, R. Radic, G. Curic, Function of circle of Willis, J. Cereb. Blood Flow Metab. 34 (2014) 578-584. doi:10.1038/jcbfm.2014.7.

[41] G. Zhu, Q. Yuan, J. Yang, J.H. Yeo, Experimental study of hemodynamics in the circle of willis, Biomed. Eng. OnLine. 14 (2015) S10. doi:10.1186/1475-925X-14-S1-S10.

[42] L. Zarrinkoob, K. Ambarki, A. Wåhlin, R. Birgander, A. Eklund, J. Malm, Blood flow distribution in cerebral arteries, J. Cereb. Blood Flow Metab. Off. J. Int. Soc. Cereb. Blood Flow Metab. 35 (2015) 648-654. doi:10.1038/jcbfm.2014.241.

[43] S. Kamath, Observations on the length and diameter of vessels forming the circle of Willis., J. Anat. 133 (1981) 419-423.

[44] W.R. Smoker, M.J. Price, W.D. Keyes, J.J. Corbett, L.R. Gentry, High-resolution computed tomography of the basilar artery: 1. Normal size and position, AJNR Am. J. Neuroradiol. 7 (1986) 55-60.

[45] P. Reymond, F. Merenda, F. Perren, D. Rüfenacht, N. Stergiopulos, Validation of a onedimensional model of the systemic arterial tree, Am. J. Physiol. Heart Circ. Physiol. 297 (2009) H208-222. doi:10.1152/ajpheart.00037.2009.

[46] K. DEVAULT, P.A. GREMAUD, V. NOVAK, M.S. OLUFSEN, G. VERNIĖRES, P. ZHAO, BLOOD FLOW IN THE CIRCLE OF WILLIS: MODELING AND CALIBRATION, Multiscale Model. Simul. SIAM Interdiscip. J. 7 (2008) 888-909. doi:10.1137/07070231X.

[47] J.M. Hong, C.-S. Chung, O.Y. Bang, S.W. Yong, I.S. Joo, K. Huh, Vertebral artery dominance contributes to basilar artery curvature and peri-vertebrobasilar junctional infarcts, J. Neurol. Neurosurg. Psychiatry. 80 (2009) 1087-1092. doi:10.1136/jnnp.2008.169805.

[48] P.B. Kardile, J.M. Ughade, S.V. Pandit, M.N. Ughade, Anatomical Variations of Anterior Communicating Artery, J. Clin. Diagn. Res. JCDR. 7 (2013) 2661-2664. doi:10.7860/JCDR/2013/6664.3725.

[49] F. Moscato, G.A. Danieli, H. Schima, Dynamic modeling and identification of an axial flow ventricular assist device, Int. J. Artif. Organs. 32 (2009) 336-343.

[50] M.D. Ford, N. Alperin, S.H. Lee, D.W. Holdsworth, D.A. Steinman, Characterization of volumetric flow rate waveforms in the normal internal carotid and vertebral arteries, Physiol. Meas. 26 (2005) 477-488. doi:10.1088/0967-3334/26/4/013.

[51] D.R. Enzmann, M.R. Ross, M.P. Marks, N.J. Pelc, Blood flow in major cerebral arteries measured by phase-contrast cine MR, AJNR Am. J. Neuroradiol. 15 (1994) 123-129.

[52] K.W. Stock, S.G. Wetzel, P.A. Lyrer, E.W. Radü, Quantification of blood flow in the middle cerebral artery with phase-contrast MR imaging, Eur. Radiol. 10 (2000) 1795-1800. doi:10.1007/s003300000378.

[53] P. Brassard, A.S. Jensen, N. Nordsborg, F. Gustafsson, J.E. Møller, C. Hassager, S. Boesgaard, P.B. Hansen, P.S. Olsen, K. Sander, N.H. Secher, P.L. Madsen, Central and peripheral blood flow during exercise with a continuous-flow left ventricular assist device: constant versus increasing pump speed: a pilot study, Circ. Heart Fail. 4 (2011) 554-560. doi:10.1161/CIRCHEARTFAILURE.110.958041.

[54] R.F. Salamonsen, E. Lim, N. Gaddum, A.-H.H. AlOmari, S.D. Gregory, M. Stevens, D.G. Mason, J.F. Fraser, D. Timms, M.K. Karunanithi, N.H. Lovell, Theoretical foundations of a Starling-like controller for rotary blood pumps, Artif. Organs. 36 (2012) 787-796. doi:10.1111/j.1525-1594.2012.01457.x. 
[55] G.M. Wieselthaler, H. Schima, M. Hiesmayr, R. Pacher, G. Laufer, G.P. Noon, M. DeBakey, E. Wolner, First clinical experience with the DeBakey VAD continuous-axial-flow pump for bridge to transplantation, Circulation. 101 (2000) 356-359.

[56] J.M. Grinda, C.H. Latremouille, P. Chevalier, N. D'Attelis, F. Boughenou, R. Guillemain, A. Deloche, J.N. Fabiani, Bridge to transplantation with the DeBakey VAD $®$ axial pump: a single center report, Eur. J. Cardiothorac. Surg. 22 (2002) 965-970. doi:10.1016/S10107940(02)00612-7.

\section{Figure Legends}

Figure 1. The utilised preserved and impaired cerebral flow autoregulation $\left(C F A_{p}, C F A_{i}\right)$ function curves in the simulations and physiological preserved and impaired cerebral flow autoregulation functions

Figure 2. The electric analogue of cardiovascular system, CF-LVAD and cerebral circulation models (i), the electric analogue of cerebral circulation and Circle of Willis (ii) and a schematic of circle of Willis (iii).

Figure 3. The left ventricular and atrial pressures $\left(p_{l v}, p_{l a}\right)$ and the aortic pressure $\left(p_{a o}\right)$ in the healthy cardiovascular system model (i), DCM cardiovascular system model with the preserved cerebral autoregulation function (ii) and DCM cardiovascular system model with the impaired cerebral autoregulation function (iii). The left ventricular and atrial volumes $\left(V_{l v}, V_{l a}\right)$ in the healthy cardiovascular system model (iv), DCM cardiovascular system model with the preserved cerebral autoregulation function (v) and DCM cardiovascular system model with the impaired cerebral autoregulation function (vi)

Figure 4. The flow rates in the internal carotid arteries $\left(Q_{i c a}\right)(i)$, vertebral arteries $\left(Q_{v a}\right)$ (ii), basilar artery $\left(Q_{b a}\right)$ (iii), posterior cerebral arteries $\left(Q_{p c a}\right)\left(\right.$ iv), anterior cerebral arteries $\left(Q_{a c a}\right)(v)$, and middle cerebral arteries $\left(Q_{m c a}\right)(\mathrm{vi})$ in the healthy cardiovascular system $(H)$ model and DCM cardiovascular system models with the preserved $(D C M, p)$ and impaired $(D C M, i)$ cerebral flow autoregulation functions.

Figure 5. The mean flow rates in the internal carotid arteries (i), vertebral arteries (ii), basilar artery (iii), posterior cerebral arteries (iv), anterior cerebral arteries (v) and middle cerebral arteries (vi) in the healthy cardiovascular system $(H)$ model and DCM cardiovascular system models with the preserved $\left(D C M_{p}\right)$ and impaired $\left(D C M_{i}\right)$ cerebral flow autoregulation functions and the DCM cardiovascular system models under CF-LVAD support. 
1 Figure 6. The total mean blood flow rate in the cerebral circulation in the healthy cardiovascular system $(H)$

2 model and DCM cardiovascular system models with the preserved $\left(D C M_{p}\right)$ and impaired $\left(D C M_{i}\right)$ cerebral

3 flow autoregulation functions and the DCM cardiovascular system models under CF-LVAD support.

4 Figure 7. Amplitude of the flow rate signals in the internal carotid arteries (i), vertebral arteries (i), basilar

5 artery (iii), posterior cerebral arteries (iv), anterior cerebral arteries (v) and middle cerebral arteries (vi) in

6 the healthy cardiovascular system $(H)$ model and DCM cardiovascular system models with the preserved

$7 \quad\left(D C M_{p}\right)$ and impaired $\left(D C M_{i}\right)$ cerebral flow autoregulation functions and the DCM cardiovascular system

8 models under CF-LVAD support.

9 Figure 8. The vascular resistances in the pial circulation (i) and systemic peripheral circulation (ii) in the 10 healthy cardiovascular system $(H)$ model and DCM cardiovascular system models with the preserved $11\left(D C M_{p}\right)$ and impaired $\left(D C M_{i}\right)$ cerebral flow autoregulation functions and the DCM cardiovascular system 12 models under CF-LVAD support. 


\section{Tables}

5 Table 1. The mean aortic pressure $\left(p_{\mathrm{ao}, m}\right)$, cardiac output $(C O)$ and the mean pump output $(M P O)$ for the

6 healthy cardiovascular system model, DCM cardiovascular system models with the preserved and

7 impaired cerebral flow autoregulation functions and the DCM cardiovascular system models under CF-

LVAD support. 


\section{Appendix}

Table 2. Glossary of abbreviations

\begin{tabular}{|c|c|c|c|}
\hline \multicolumn{2}{|c|}{ Nomenclature } & \multirow{2}{*}{$\begin{array}{l}\text { rva } \\
\text { Iva }\end{array}$} & \multirow{2}{*}{$\begin{array}{l}\text { right vertebral artery } \\
\text { left vertebral artery }\end{array}$} \\
\hline$p$ & pressure & & \\
\hline V & volume & roa & right ophthalmic artery \\
\hline $\mathrm{t}$ & time & loa & left ophthalmic artery \\
\hline $\mathrm{R}$ & resistance & ba & basilar artery \\
\hline $\mathrm{L}$ & inertance & pca & posterior cerebral arteries \\
\hline C & compliance & rpca & right posterior cerebral artery \\
\hline AV & aortic valve & Ipca & left posterior cerebral artery \\
\hline MV & mitral valve & rpcoa & right posterior communicating artery \\
\hline PV & pulmonary valve & Ipcoa & left posterior communicating artery \\
\hline TV & tricuspid valve & rsca & right superior cerebellar artery \\
\hline \multicolumn{2}{|c|}{ Subscripts } & Isca & left superior cerebellar artery \\
\hline la & left atrium & racha & right anterior choroidal artery \\
\hline Iv & left ventricle & lacha & left anterior choroidal artery \\
\hline ra & right atrium & rmca & right middle cerebral artery \\
\hline rv & right ventricle & Imca & left middle cerebral artery \\
\hline ao & aorta & raca & right anterior cerebral artery \\
\hline aа & aortic arch & laca & left anterior cerebral artery \\
\hline ars & systemic arterioles & acoa & anterior communicating artery \\
\hline cs & systemic capillaries & $\mathrm{pc}$ & pial circulation \\
\hline vs & systemic veins & cc & cerebral capillaries \\
\hline ap & pulmonary arteries & vc & cerebral veins \\
\hline arp & pulmonary arterioles & 1 & segment one \\
\hline $\mathrm{vp}$ & pulmonary veins & 2 & segment two \\
\hline rica & right internal carotid artery & $\mathrm{m}$ & mean \\
\hline lica & left internal carotid artery & & \\
\hline
\end{tabular}

4 
2 Table 3. Parameter values used in the heart chambers. Parameter values in the brackets show the values
3 in the DCM models. $V, \sigma, c, l, v$ represent volume, stress, contraction coefficient, length and velocity

2 Table 3. Parameter values used in the heart chambers. Parameter values in the brackets show the values
3 in the DCM models. $V, \sigma, C, I, v$ represent volume, stress, contraction coefficient, length and velocity respectively.

\begin{tabular}{lcccc}
\hline & Left Ventricle & Right Ventricle & Left Atrium & Right Atrium \\
\hline $\mathrm{V}_{\mathrm{w}}[\mathrm{mL}]$ & $200(225)$ & 100 & 20 & 20 \\
$\mathrm{~V}_{0}[\mathrm{~mL}]$ & $60(90)$ & 75 & 25 & 25 \\
$\sigma_{\mathrm{f} 0}[\mathrm{kPa}]$ & 0.9 & 0.9 & 0.9 & 0.9 \\
$\sigma_{\mathrm{r} 0}[\mathrm{kPa}]$ & 0.2 & 0.2 & 0.2 & 0.2 \\
$\sigma_{\mathrm{ar}}[\mathrm{kPa}]$ & 55 & 55 & 7.5 & 7.5 \\
$\mathrm{C}_{\mathrm{f}}$ & 12 & 12 & 12 & 12 \\
$\mathrm{C}_{\mathrm{r}}$ & 9 & 9 & 9 & 9 \\
$\mathrm{C}$ & $1(0.6)$ & 1 & 1 & 1 \\
$\mathrm{C}_{\mathrm{v}}$ & 0 & 0 & 0 & 0 \\
$\mathrm{I}_{\mathrm{s} 0}[\mu \mathrm{m}]$ & 1.9 & 1.9 & 1.9 & 1.9 \\
$\mathrm{I}_{\mathrm{sa} 0}[\mu \mathrm{m}]$ & 1.5 & 1.5 & 1.5 & 1.5 \\
$\mathrm{I}_{\mathrm{sar}}[\mu \mathrm{m}]$ & 2 & 2 & 2 & 2 \\
$\mathrm{~V}_{0}[\mu \mathrm{m} / \mathrm{s}]$ & 10 & 10 & 10 & 10 \\
\hline & & & &
\end{tabular}

$\begin{array}{cc}3 & \\ 35 & 7 \\ 6 & 8 \\ 7 & \\ 38 & 9 \\ 9 & 9 \\ 0 & 10 \\ 1 & \\ 2 & 11 \\ 3 & 11 \\ 4 & \\ 5 & 12 \\ 46 & \\ 47 & 13 \\ 8 & \\ 4 & 14 \\ 50 & \\ 51 & 15 \\ 2 & \\ 53 & 16 \\ 54 & \\ 55 & 17 \\ 56 & \\ 57 & \\ 58 & \\ 59 & \\ 60 & \end{array}$


2 Table 4. Parameter values used in the circulatory loop. $R, L$ and $C$ represent resistance, inertance and 3 compliance of the blood vessels respectively.

\begin{tabular}{|c|c|c|c|}
\hline & $\mathrm{R}[\mathrm{mmHgs} / \mathrm{mL}]$ & $\mathrm{L}\left[\mathrm{mmHgs}^{2} / \mathrm{mL}\right]$ & $\mathrm{C}[\mathrm{mL} / \mathrm{mmHg}]$ \\
\hline Mitral Valve & 0.0025 & - & - \\
\hline Aortic Valve & 0.0025 & - & - \\
\hline Pulmonary Valve & 0.0010 & - & - \\
\hline Tricuspid Valve & 0.0010 & - & - \\
\hline Aorta & 0.01 & 0.0001 & 0.1 \\
\hline Aortic Arch & 0.05 & 0.0001 & 0.25 \\
\hline Systemic Arterioles & $\mathrm{R}_{\text {ars }}$ & 0.0001 & 2 \\
\hline Systemic Capillaries & 0.24 & - & 4 \\
\hline Systemic Veins & 0.1 & - & 30 \\
\hline Pulmonary Arteries & 0.02 & 0.0001 & 3 \\
\hline Pulmonary Arterioles & 0.1 & 0.0001 & 6 \\
\hline Pulmonary Veins & 0.1 & - & 30 \\
\hline Internal Carotid Arteries & 1.738 & 0.0001 & - \\
\hline Vertebral Arteries & 5 & 0.0001 & - \\
\hline Basilar Artery & 6.474 & - & 0.001 \\
\hline Posterior Cerebral Arteries 1 & 0.821 & - & 0.001 \\
\hline Posterior Cerebral Arteries 2 & 3.877 & - & 0.001 \\
\hline Posterior Communicating Arteries & 321 & - & - \\
\hline Superior Cerebellar Arteries & 7.143 & - & - \\
\hline Anterior Choroidal Arteries & 125 & - & - \\
\hline Middle Cerebral Arteries & 8.940 & - & 0.001 \\
\hline Ophthalmic Arteries & 125 & - & 0.001 \\
\hline Anterior Cerebral Arteries 1 & 9.761 & - & - \\
\hline Anterior Cerebral Arteries 2 & 4.178 & - & 0.001 \\
\hline Anterior Communicating Artery & 53.571 & - & - \\
\hline Pial Circulation & $\mathrm{R}_{\mathrm{pc}}$ & - & 0.5 \\
\hline Cerebral Capillaries & 0.1 & - & 2 \\
\hline Cerebral Veins & 0.1 & - & 6 \\
\hline
\end{tabular}

4

Table 5. Parameter values used in the baroreflex model. $p_{a o, s e t}, R_{\text {set }}$ and $S_{R}$ represent set points of the 6 aortic pressure, resistance and sensitivity of the resistances respectively. Parameter value in the brackets 7 show the value in the impaired cerebral autoregulatory function.

\begin{tabular}{cccc}
\hline & $p_{a o, \text { set }}[\mathrm{mmHg}]$ & $\mathrm{R}_{\text {set }}[\mathrm{mmHgs} / \mathrm{mL}]$ & $\mathrm{S}_{\mathrm{R}}\left[\mathrm{mmHg}^{-1}\right]$ \\
\hline Systemic Arterioles & 100 & 1 & 0.0175
\end{tabular}




\begin{tabular}{llll} 
Pial Circulation & 100 & 5 & $0.0120(0.0055)$ \\
\hline
\end{tabular}

1 
The utilised preserved and impaired cerebral flow autoregulation (CFAp, CFAi) function curves in the simulations and physiological preserved and impaired cerebral flow autoregulation functions

$78 \times 60 \mathrm{~mm}(96 \times 96$ DPI) 


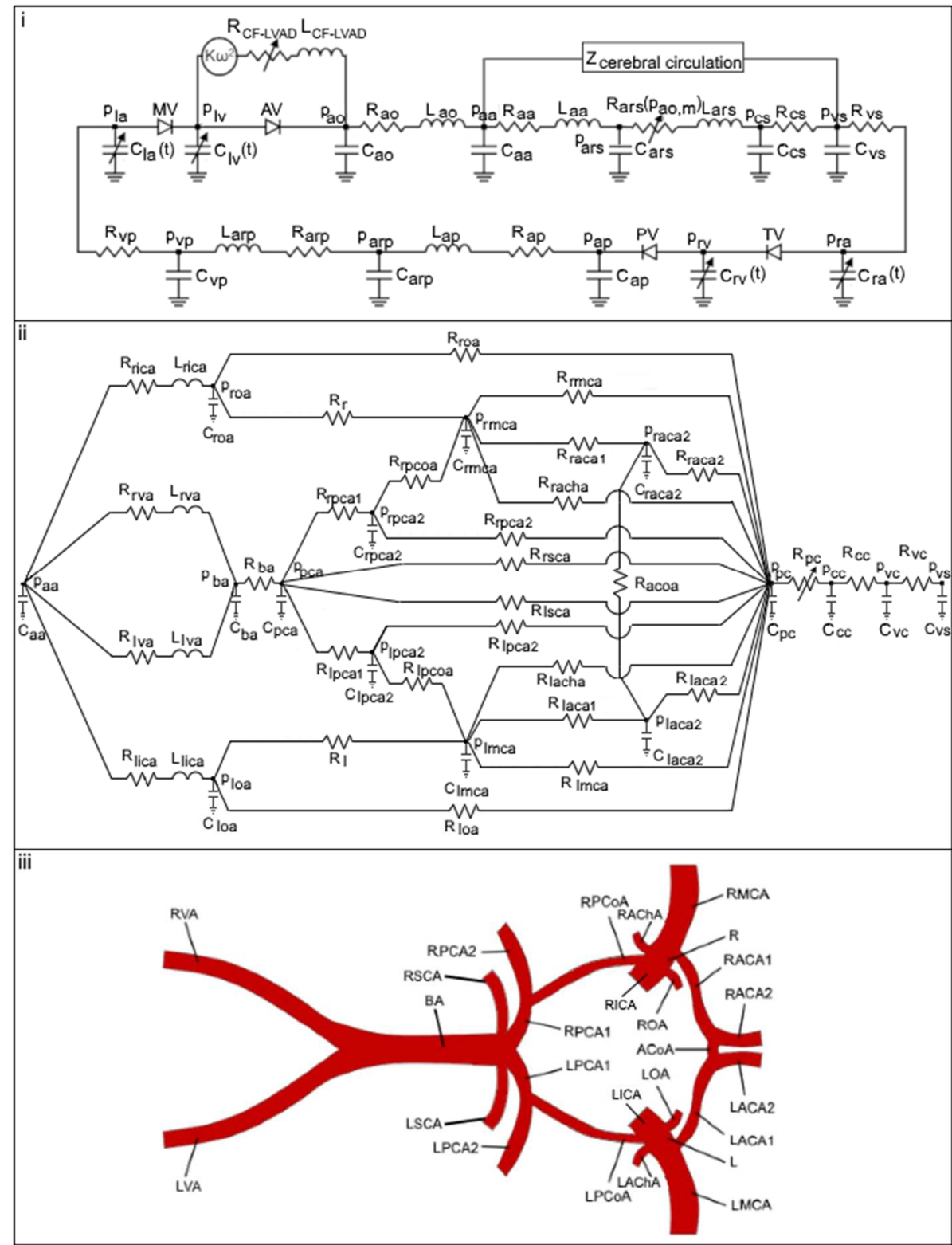

The electric analogue of cardiovascular system, CF-LVAD and cerebral circulation models (i), the electric analogue of cerebral circulation and Circle of Willis (ii) and a schematic of circle of Willis (iii)

$175 \times 231 \mathrm{~mm}(96 \times 96 \mathrm{DPI})$ 

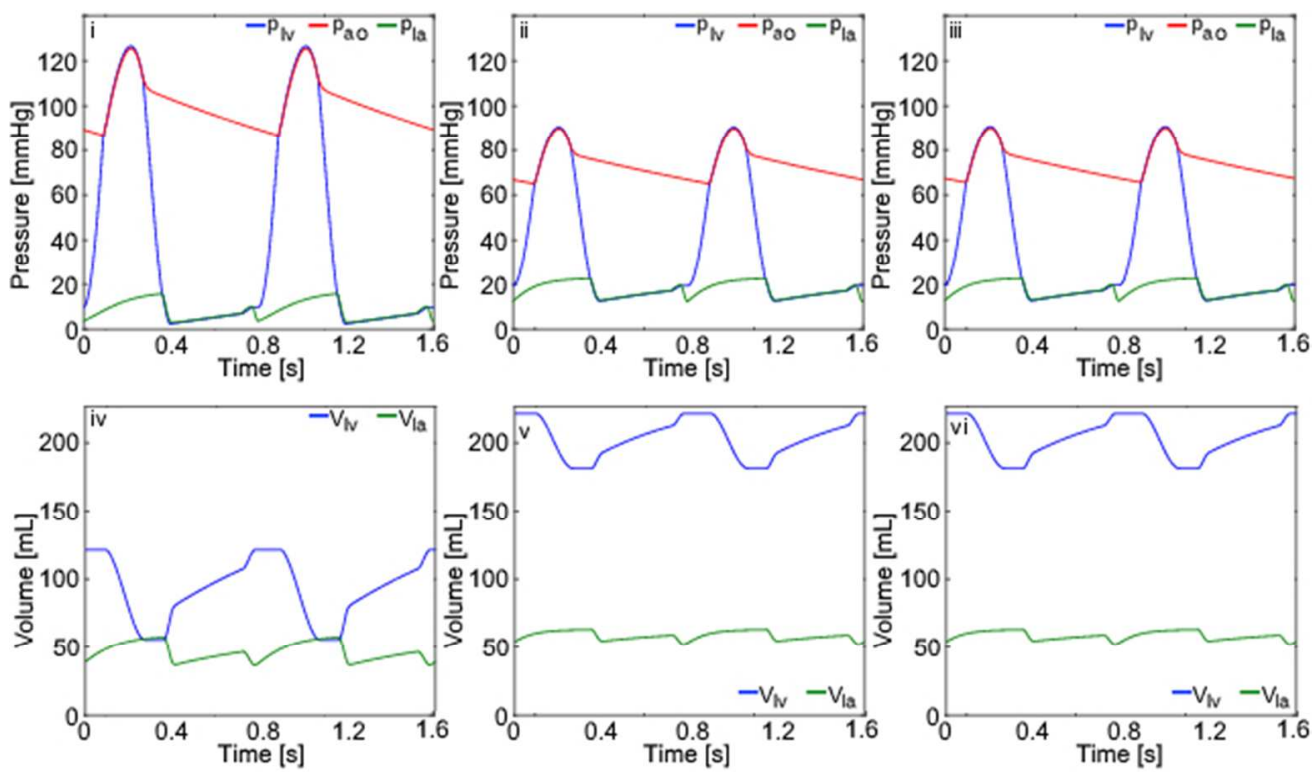

The left ventricular and atrial pressures (plv,pla) and the aortic pressure (pao) in the healthy cardiovascular system model (i), DCM cardiovascular system model with the preserved cerebral autoregulation function (ii) and DCM cardiovascular system model with the impaired cerebral autoregulation function (iii). The left ventricular and atrial volumes ( VIv, Vla) in the healthy cardiovascular system model (iv), DCM cardiovascular system model with the preserved cerebral autoregulation function (v) and DCM cardiovascular system model with the impaired cerebral autoregulation function (vi) 

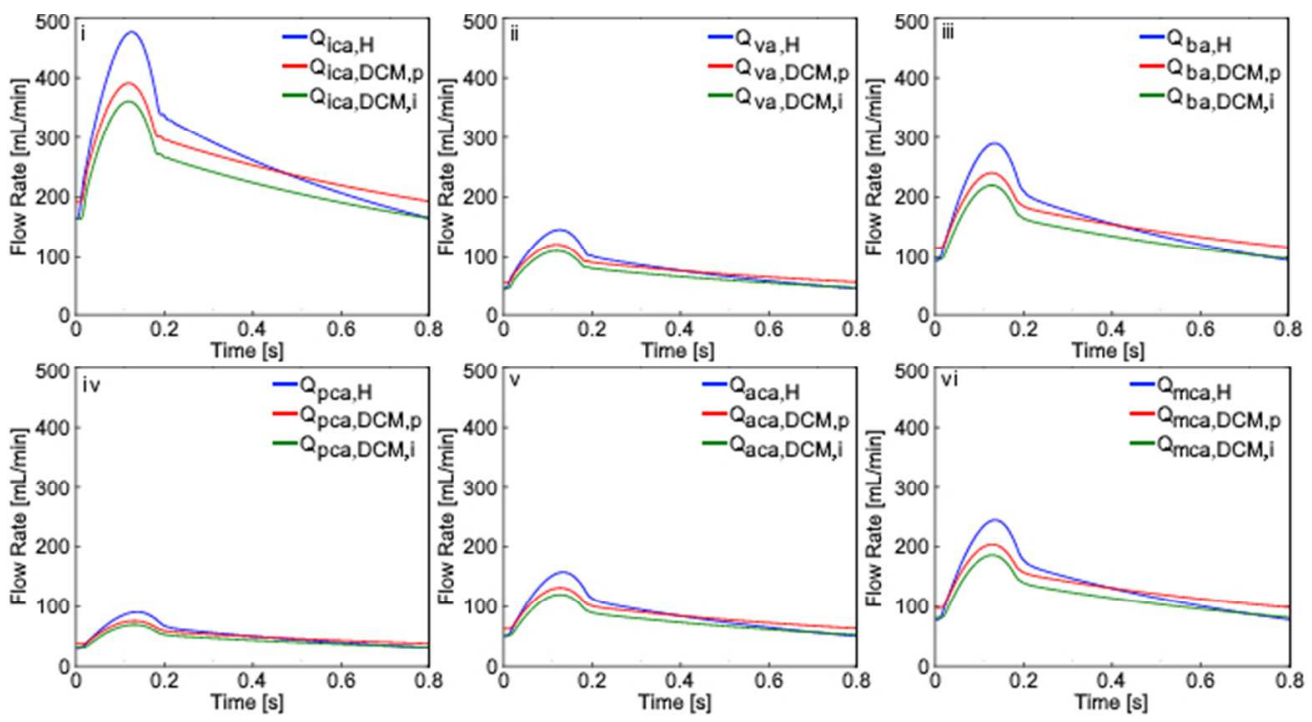

The flow rates in the internal carotid arteries (Qica) (i), vertebral arteries (Qva) (ii), basilar artery (Qba)

(iii), posterior cerebral arteries (Qpca) (iv), anterior cerebral arteries (Qaca) ( $\mathrm{v}$ ), and middle cerebral arteries (Qmca) (vi) in the healthy cardiovascular system $(\mathrm{H})$ model and DCM cardiovascular system models with the preserved $(D C M, p)$ and impaired $(D C M, i)$ cerebral flow autoregulation functions

\section{$177 \times 95 \mathrm{~mm}(96 \times 96 \mathrm{DPI})$}



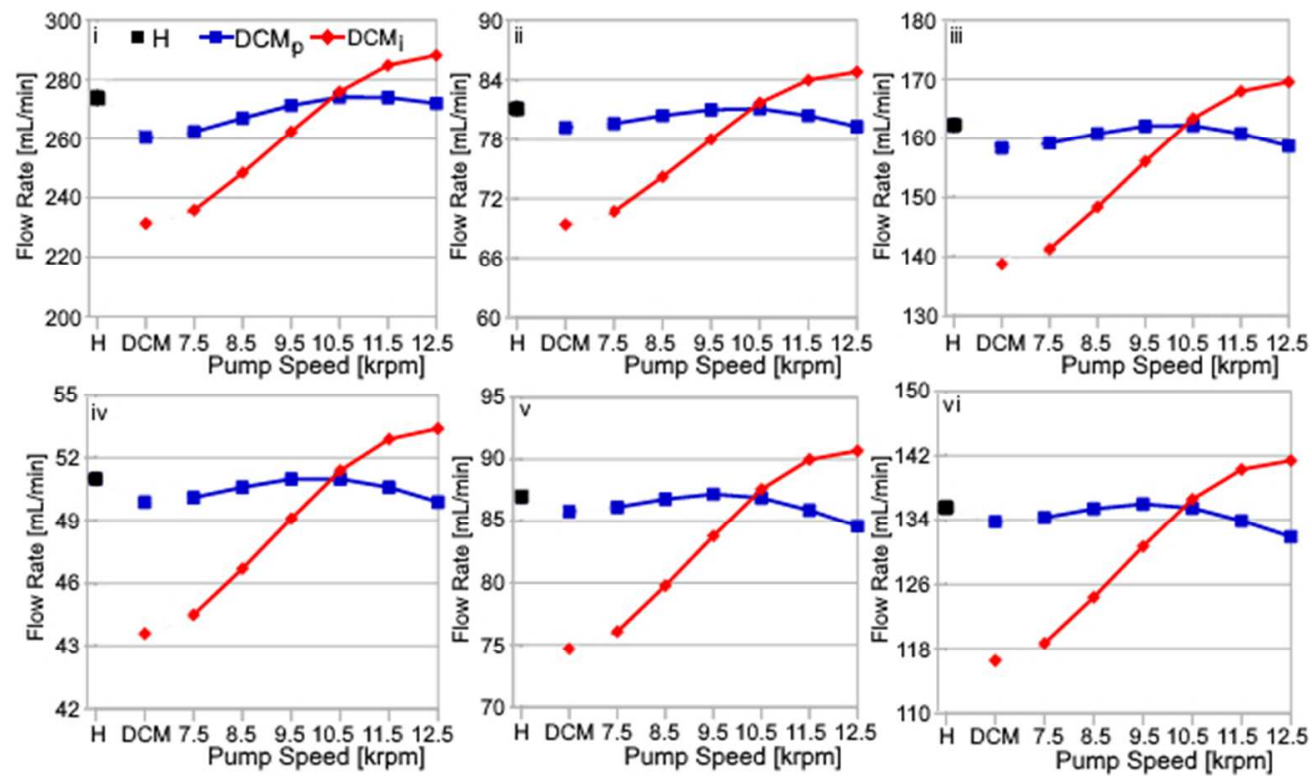

The mean flow rates in the internal carotid arteries (i), vertebral arteries (ii), basilar artery (iii), posterior cerebral arteries (iv), anterior cerebral arteries (v) and middle cerebral arteries (vi) in the healthy cardiovascular system $(\mathrm{H})$ model and DCM cardiovascular system models with the preserved (DCMp) and impaired (DCMi) cerebral flow autoregulation functions and the DCM cardiovascular system models under CF-LVAD support 
The total mean blood flow rate in the cerebral circulation in the healthy cardiovascular system $(\mathrm{H})$ model and DCM cardiovascular system models with the preserved (DCMp) and impaired (DCMi) cerebral flow autoregulation functions and the DCM cardiovascular system models under CF-LVAD support 

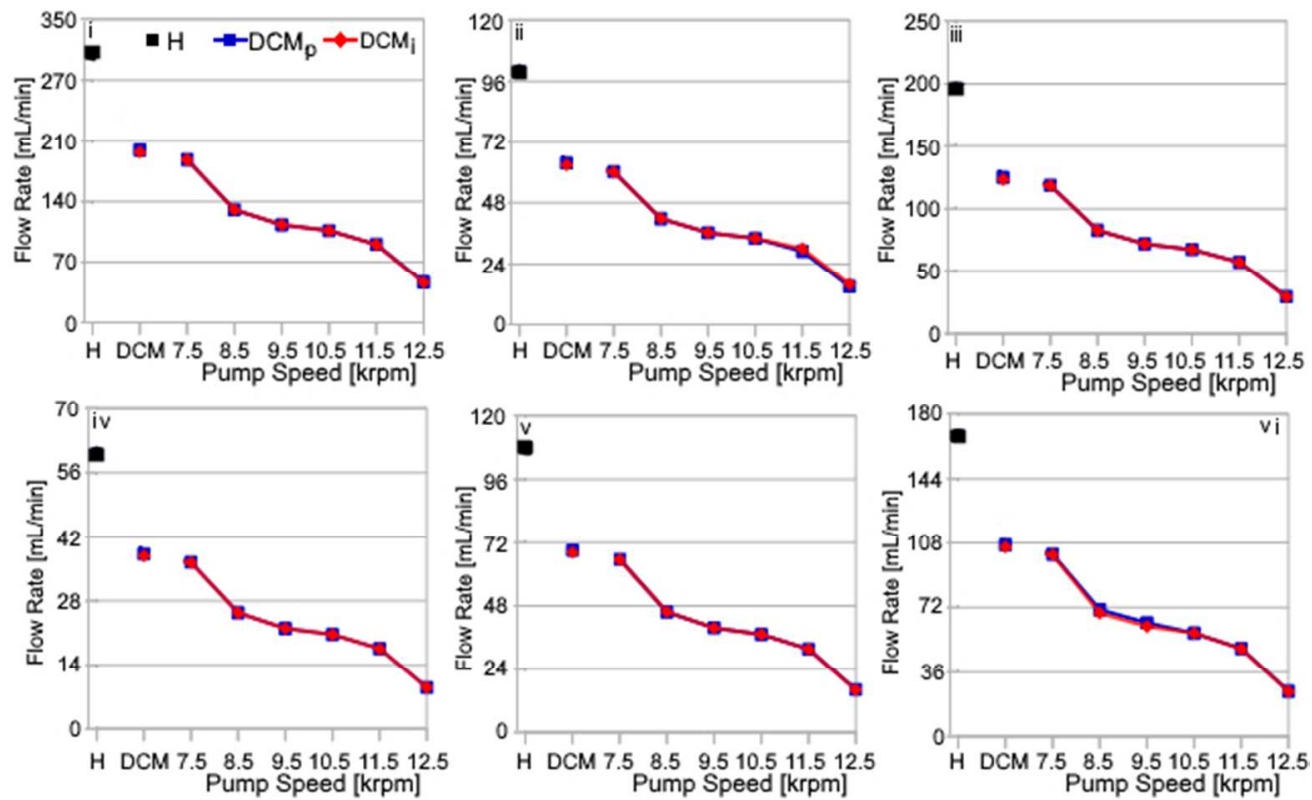

Amplitude of the flow rate signals in the internal carotid arteries (i), vertebral arteries (i), basilar artery (iii), posterior cerebral arteries (iv), anterior cerebral arteries ( $v$ ) and middle cerebral arteries ( $v i$ ) in the healthy cardiovascular system $(\mathrm{H})$ model and DCM cardiovascular system models with the preserved (DCMp) and impaired (DCMi) cerebral flow autoregulation functions and the DCM cardiovascular system models under CF-LVAD support 

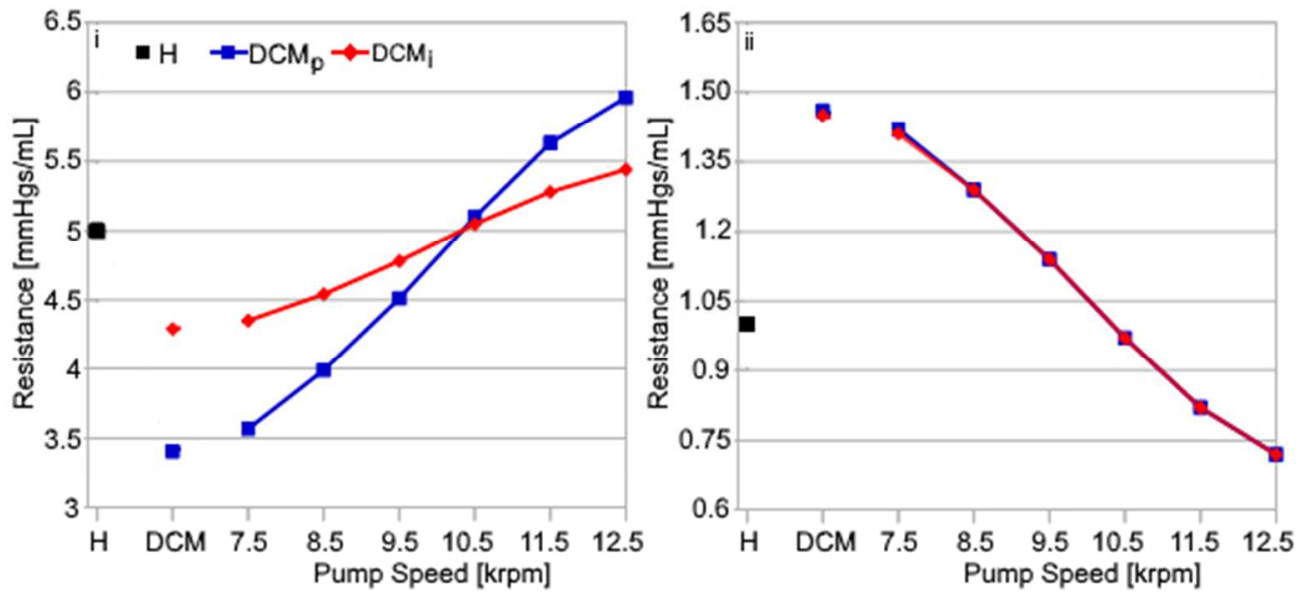

The vascular resistances in the pial circulation (i) and systemic peripheral circulation (ii) in the healthy cardiovascular system $(\mathrm{H})$ model and DCM cardiovascular system models with the preserved (DCMP) and impaired (DCMi) cerebral flow autoregulation functions and the DCM cardiovascular system models under CF-LVAD support

$153 \times 69 \mathrm{~mm}(96 \times 96 \mathrm{DPI})$ 